\title{
Empirical use of antibiotic therapy in the prevention of early onset sepsis in neonates: a pilot study
}

Mohamed Mansor Manan ${ }^{1}$, Nazedah Ain Ibrahim ${ }^{1}$, Noorizan Abd Aziz ${ }^{1}$, Hanis Hanum Zulkifly ${ }^{1}$, Yaser Mohammed Ali Al-Worafi², Chiau Ming Long ${ }^{1,3}$

${ }^{1}$ Faculty of Pharmacy, Universiti Teknologi MARA, Puncak Alam, Malaysia
2Pharmacy Practice Department, College of Pharmacy, Qassim University, Saudi Arabia
'Brain Degeneration and Therapeutics Group, Pharmaceutical and Life Sciences CoRe,
Universiti Teknologi MARA, Shah Alam, Malaysia

Submitted: 15 July 2014

Accepted: 4 November 2014

Arch Med Sci 2016; 12, 3: 603-613

DOI: $10.5114 /$ aoms.2015.51208

Copyright $\odot 2015$ Termedia \& Banach

\author{
Corresponding author: \\ Chiau Ming Long PhD \\ Faculty of Pharmacy \\ Universiti Teknologi MARA \\ Level 11, FF1 \\ 42300 Puncak Alam, \\ Malaysia \\ Phone: +60332584775 \\ E-mail: longchiauming@ \\ gmail.com
}

\begin{abstract}
Introduction: To identify and assess the characteristics, risk and outcome of neonates treated with empiric antibiotics for suspected early onset sepsis (EOS).

Material and methods: This is a retrospective study conducted at a Malaysian government hospital. Records of neonatal patients admitted within $72 \mathrm{~h}$ of life and prescribed with empirical antibiotic therapy for suspected EOS were reviewed.

Results: Three hundred and twenty-three cases met the inclusion criteria and were divided into gestational age (premature $<36$ weeks; term $\geq 37$ weeks) and birth weight (low birth weight (LBW) < $2.5 \mathrm{~kg}$; normal body weight $(\mathrm{NBW}) \geq 2.5 \mathrm{~kg})$ groups. Premature $(n=197)$ and LBW $(n=194)$ neonates required significantly longer hospital stay, a higher degree of ventilator support and more surfactant $(p=0.001)$. More than $90.0 \%$ of premature and LBW neonates were diagnosed with respiratory distress syndrome, congenital pneumonia and presumed sepsis. Term $(n=123)$ and NBW $(n=129)$ neonates had greater maternal risk factors, especially meconium-stained amniotic fluid (MSAF) and perinatal asphyxia. The incidence of demonstrated EOS was $3.1 \%$. Crystalline penicillin plus gentamicin was the standard therapy for all groups and was started within $24 \mathrm{~h}$ of life, with a mean treatment duration of $\sim 4$ days. The treatment success rate was $89.0 \%$, and only LBW neonates showed a higher risk of overall treatment failure $(O R=3.75$; $95 \% \mathrm{Cl}: 1.22-11.53)$. Seventy-four percent of term and NBW neonates discharged well, while $42.0 \%$ of premature and LBW neonates required referral. Conclusions: Crystalline penicillin plus gentamicin prescribed within $24 \mathrm{~h}$ of life is effective in the prevention of EOS. However, low birth weight neonates have a higher risk of treatment failure.
\end{abstract}

Key words: pediatrics, newborn, clinical outcome, gentamicin, penicillin, intensive care, healthcare-associated infection.

\section{Introduction}

The World Health Organization (WHO) has estimated that more than half of the approximately 7.5 million infant deaths in the world occur in the first 4 weeks after birth, and $98.0 \%$ of these neonatal deaths occur in developing regions. Meanwhile, the early neonatal mortality rate ranges from 3 to 4 per 1000 births in different states of Malaysia, according to 
the WHO neonatal and perinatal mortality report 2006 [1]. The main causes of neonatal death are infections, prematurity and birth asphyxia. Neonatal sepsis currently causes 1.6 million deaths annually in developing countries and is also the main reason for hospitalization in the Neonatal Intensive Care Unit (NICU) [2, 3].

Early onset sepsis (EOS) is defined as a clinical syndrome of bacteremia with systemic signs and symptoms of infection in the first 4 weeks of life. It also can be defined microbiologically from positive cultures of blood, cerebrospinal fluid or urine specimens. The WHO collaborating center for training and research classified EOS as onset of symptoms before $72 \mathrm{~h}$ of life. However, there are variable EOS definitions in the literature, and it may range from $48 \mathrm{~h}$ up to 6 days after delivery [4-6]. Early onset sepsis manifests frequently as pneumonia presenting with respiratory distress and less commonly as septicemia or meningitis. Making an early diagnosis of neonatal sepsis demands a highly suspicious index of clinical manifestations such as lethargy, refusal to suckle, poor cry, not arousable, abdominal distension, diarrhea, vomiting, hypothermia, poor perfusion, poor weight gain, shock, bleeding and renal failure. The clinical manifestations that are particularly suggestive for pneumonia are cyanosis, tachypnea, chest retractions, grunts or gasping and apnea. Other clinical manifestations are fever, seizures, blank look, high pitch cry, excessive crying or irritability, neck retraction and bulging fontanel; these are particularly suggestive of meningitis [7].

Early onset sepsis is normally caused by microorganisms that colonize the mother's genitourinary tract. The most common microorganisms isolated include group B Streptococcus (GBS), Escherichia coli, coagulase-negative Staphylococcus (CoNS), Haemophilus influenzae and Listeria monocytogenes [2, 8]. The choice of empiric antibiotic in suspected EOS must cover both Gram-positive and Gram-negative bacteria. The combinations penicillin/ampicillin plus gentamicin and penicillin/ampicillin plus cefotaxime intravenously are the recommended therapy for empiric treatment in suspected EOS cases [9].

There are several factors that can increase the risk of developing EOS, such as prolonged labor, preterm rupture of the membrane (PROM), prolonged PROM > $18 \mathrm{~h}$, maternal intrapartum fever, urinary tract infection (UTI) and chorioamnionitis [8]. Other factors include low birth weight and aspiration of meconium [7]. Naher et al. further reported that both low birth weight (LBW) babies and PROM are important risk factors for developing sepsis [8]. Until now, EOS has been the most significant risk factor for mortality and morbidity in full term neonates [9], extremely preterm neo- nates [10] and LBW preterm neonates [4, 5, 11]. It is important to stress that Stoll et al. showed that infection in the neonatal period is associated with poor neurodevelopmental and growth outcomes in early childhood [5].

Nevertheless, there is still a lack of strong evidence to determine the best empiric antibiotic regimen to prevent and reduce the complication of EOS. Although a randomized controlled trial is the gold standard to determine the best treatment option, most often it is not ethically justifiable to perform one in a neonatal population [12]. Due to limited information available on EOS, especially in developing countries, a current assessment on treatment practices provides much-needed evidence for future practice in terms of diagnosis and treatment $[13,14]$. Thus, our study aimed to investigate the demographics, risk and outcome of neonates treated with empiric antibiotics in a Malaysian public tertiary hospital.

\section{Material and methods}

\section{Study design and population}

This retrospective study was conducted in a tertiary hospital in Malaysia. Neonates admitted to the NICU within $72 \mathrm{~h}$ of life over a period of one and a half years (January 2011-March 2012) were identified from medical records. Medical records of neonates who met the inclusion criteria were selected; those with incomplete data were excluded.

\section{Sampling procedure}

Neonates were included in the study on the basis of the following criteria for sample selection: (i) neonates admitted to the neonatal ward within $72 \mathrm{~h}$ of life, (ii) neonates diagnosed with suspected EOS (optional) and (iii) neonates started on an empiric antibiotic regimen, i.e. penicillin/ampicillin plus gentamicin or ampicillin/penicillin plus cefotaxime, within $72 \mathrm{~h}$ of life. Subjects had to meet criteria (i) and (iii) for inclusion in the study. $\mathrm{Ne}$ onates who were discharged or died within $72 \mathrm{~h}$ after empiric antibiotic exposure, with severe heart complications, started on another empiric antibiotic regimen, with a proven infection such as meningitis, necrotizing enterocolitis (NEC) or peritonitis, and with congenital malformations were excluded from the study (Figure 1). Peripheral blood culture and sensitivity results (pre and post) were reviewed and recorded.

\section{Data collection procedure and ethical approval}

The study was approved by the Medical Research Ethics Committee (MREC) of the Malaysian Ministry of Health (NMRR-11-975-10283) and the 
Research Management Institute (RMI) at Universiti Teknologi MARA (600-RMI 5/1/01).

The data were manually recorded on a pre-validated data collection form. Data related to patient demographics, diagnosis, risk factors, clinical manifestation, proven EOS, empiric antibiotic regimen and treatment outcome were documented [15].

\section{Statistical analysis}

Data were analyzed using SPSS for Windows version 16 and Microsoft Office Excel 2007. The frequencies, percentages, median, quartile, mean and standard deviation of each continuous variable studied were calculated and tabulated.

Univariate analysis, Pearson chi-square test $\left(\chi^{2}\right.$ test) or Fisher's exact test (categorical-categorical) and Mann-Whitney test (categorical-numerical) were used where appropriate to compare the groups classified using the gestational age (GA) and birth weight (BW) criteria. The $95 \%$ confidence interval $(\mathrm{Cl})$ was set for the test whereby the result was significant if $p \leq 0.05$. After stratifying neonates into GA and BW groups, odd ratios (OR) and $95 \%$ confidence intervals $(\mathrm{Cl})$ of each risk factor, clinical manifestation and treatment failure were calculated using the Mantel-Haenszel method. Treatment failure was defined as an antibiotic change within $72 \mathrm{~h}$ after antibiotic exposure due to no improvement or deterioration, meningitis or suspicion of meningitis, NEC or suspicion of other abdominal infection, microorganism resistant to an antibiotic or death in the first 7 days of life due to sepsis [6]. Treatment success was defined based on the opposite definition of treatment failure.

\section{Results}

\section{Characteristics of patients with suspected early onset neonatal sepsis}

A total of 852 neonates were admitted to the NICU during the 3 months of the study period; 391 of them were admitted within $72 \mathrm{~h}$ of life. Out of 391 cases, 323 (82.6\%) cases with complete data that fulfilled the inclusion criteria were selected and reviewed. The eligible cases were regrouped into the GA group (i.e. either premature: $G A<36$ weeks or term GA: $\geq 37$ weeks) and BW group (i.e. either low birth weight: LBW $<2.5 \mathrm{~kg}$ or normal birth weight: NBW $\geq 2.5 \mathrm{~kg}$ ) before analysis. It was noteworthy that three cases were excluded from GA group analysis due to missing gestational age information.

\section{Demographic characteristics}

\section{Maternal demographic features}

Table I shows that only antibiotic administration during pregnancy and place of delivery were

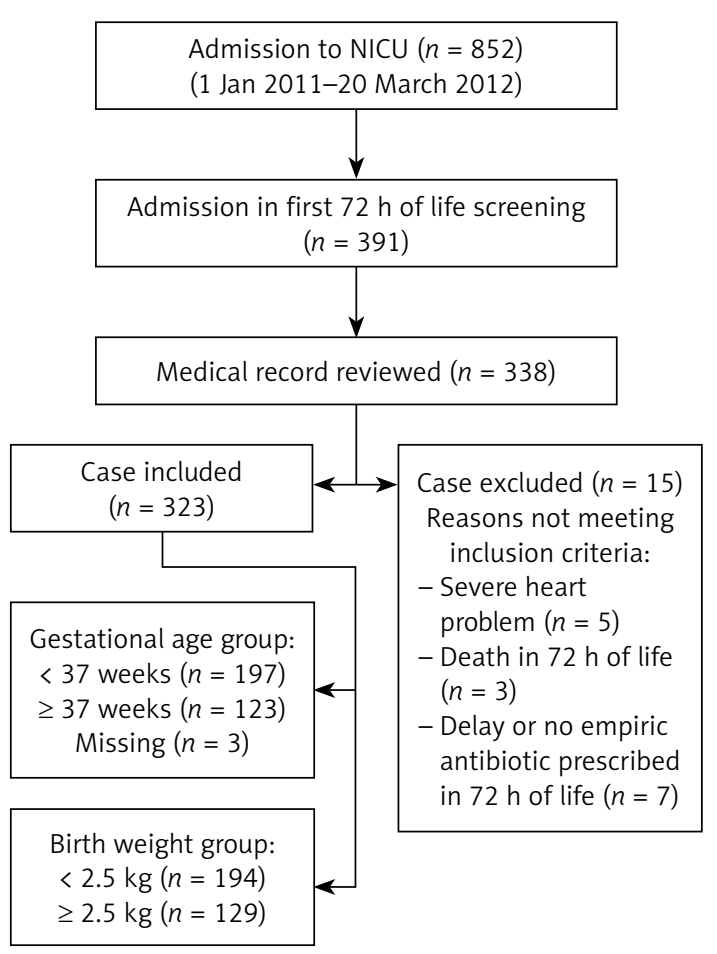

Figure 1. Study outline and exclusion

significantly different for the GA group. However, for the BW group, there was a significant difference for intrapartum antibiotic administration and complications during pregnancy. Almost $50.0 \%$ of the neonates were delivered by lower segment caesarean section (LSCS).

\section{Neonatal demographic features}

Both GA and BW groups showed significant differences in the categories length of hospital stay, ventilator support requirement, surfactant administration, C-reactive protein (CRP) above normal range and incidence of neonatal jaundice in the first 7 days of life. Premature and LBW neonates had a longer hospital stay, required more ventilator support and surfactant, showed less CRP above the normal range and had a greater incidence of neonatal jaundice in the first 7 days of life compared to term and NBW neonates (Table I).

\section{Diagnosis or to treat as diagnosis}

There was a significant difference in both groups regarding the main diagnosis or to treat as diagnosis when empiric antibiotics were started (Table II). The most common diagnosis for premature and LBW neonates was respiratory distress syndrome (RDS), suspected sepsis and congenital pneumonia, whereas term and NBW neonates were commonly diagnosed with congenital pneumonia, suspected sepsis, meconium aspirate syndrome (MAS) and hypoxic ischemic encephalopathy (HIE). 
Table I. Demographic characteristics of the study groups

\begin{tabular}{|c|c|c|c|c|c|c|}
\hline \multirow[t]{2}{*}{ Description } & \multicolumn{2}{|c|}{ GA } & \multirow{2}{*}{$\begin{array}{l}\text { Value } \\
\text { of } p\end{array}$} & \multicolumn{2}{|c|}{ BW } & \multirow{2}{*}{$\begin{array}{l}\text { Value } \\
\text { of } p\end{array}$} \\
\hline & $\begin{array}{c}<37 \text { weeks } \\
(n=197)\end{array}$ & $\begin{array}{c}\geq 37 \text { weeks } \\
(n=123)\end{array}$ & & $\begin{array}{l}<2.5 \mathrm{~kg} \\
(n=194)\end{array}$ & $\begin{array}{l}\geq 2.5 \mathrm{~kg} \\
(n=129)\end{array}$ & \\
\hline \multicolumn{7}{|l|}{ Maternal demographic features: } \\
\hline Age, mean \pm SD [years] & $28.77 \pm 5.81$ & $29.30 \pm 4.94$ & 0.709 & $28.38(5.34)$ & $29.91(5.62)$ & 0.681 \\
\hline Antibiotic during pregnancy, $n(\%)$ & $32(16.2)$ & $10(8.1)$ & 0.037 & $27(13.9)$ & $15(11.6)$ & 0.549 \\
\hline Intrapartum antibiotic, $n$ (\%) & $75(28.1)$ & $34(27.6)$ & 0.056 & $74(38.1)$ & $35(27.1)$ & 0.040 \\
\hline Caesarean section, $n(\%)$ & $115(58.4)$ & $60(48.8)$ & 0.093 & $107(55.2)$ & $68(52.7)$ & 0.666 \\
\hline Place of delivery, $n(\%)$ : & & & 0.010 & & & 0.114 \\
\hline Inborn & $176(89.3)$ & $97(78.9)$ & & $169(87.1)$ & $104(80.6)$ & \\
\hline Outborn & $21(10.7)$ & $26(21.1)$ & & $25(12.9)$ & $25(19.4)$ & \\
\hline Complication during pregnancy, $n$ (\%): & & & 0.021 & & & 0.019 \\
\hline Hypertension & $17(8.6)$ & $1(0.8)$ & & $17(8.8)$ & $1(0.8)$ & \\
\hline Diabetes & $22(11.2)$ & $19(15.4)$ & & $22(11.3)$ & $19(14.7)$ & \\
\hline Anemia & $15(7.6)$ & $11(8.9)$ & & $14(7.2)$ & $12(9.3)$ & \\
\hline Multiple complications & $5(2.5)$ & $3(2.4)$ & & $5(2.6)$ & $3(2.3)$ & \\
\hline Others & $9(4.6)$ & $11(8.4)$ & & $9(4.6)$ & $11(11.4)$ & \\
\hline \multicolumn{7}{|l|}{ Neonatal demographic features: } \\
\hline Birth weight, mean \pm SD $[\mathrm{kg}]$ & $1.67 \pm 0.56$ & $3.11 \pm 0.61$ & 0.001 & $1.61 \pm 0.48$ & $3.15 \pm 0.53$ & \\
\hline Gestational age, mean \pm SD [weeks] & $31.80 \pm 2.86$ & $39.32 \pm 1.75$ & & $32.08 \pm 3.40$ & $38.65 \pm 2.41$ & 0.001 \\
\hline Length of stay, mean \pm SD [days] & $29.78 \pm 21.98$ & $9.85 \pm 6.79$ & 0.001 & $30.04 \pm 22.12$ & $9.91 \pm 6.34$ & 0.001 \\
\hline Gender, $n(\%)$ : & & & 0.388 & & & 0.410 \\
\hline Male & $117(59.4)$ & $79(64.2)$ & & $116(59.8)$ & $83(64.3)$ & \\
\hline Female & $80(40.6)$ & $44(35.8)$ & & $78(40.2)$ & $46(35.7)$ & \\
\hline Ventilator, $n(\%)$ : & & & 0.001 & & & 0.003 \\
\hline Intubated & $121(61.4)$ & $66(53.7)$ & & $118(60.8)$ & $71(55.0)$ & \\
\hline CPAP & $35(17.8)$ & $5(4.1)$ & & $31(16.0)$ & $9(7.0)$ & \\
\hline Surfactant, $n(\%)$ & $53(26.9)$ & $0(0.0)$ & 0.001 & $51(26.3)$ & $2(1.6)$ & 0.001 \\
\hline C-reactive protein $>$ normal range, $n(\%)$ & $20(10.2)$ & $32(26.0)$ & 0.001 & $22(11.3)$ & $30(23.3)$ & 0.004 \\
\hline APGAR score at 1 min, mean \pm SD: & $7.52 \pm 2.16$ & $6.77 \pm 2.66$ & 0.058 & $7.48 \pm 2.23$ & $6.85 \pm 2.56$ & 0.307 \\
\hline Critically low $(<3), n(\%)$ & $17(8.6)$ & $20(16.3)$ & & $18(9.3)$ & $19(14.7)$ & \\
\hline Fairly low (4-6), $n(\%)$ & $32(16.2)$ & $24(19.5)$ & & $34(17.5)$ & $22(17.1)$ & \\
\hline Normal (7-10), $n(\%)$ & $144(73.1)$ & $76(61.8)$ & & $137(70.6)$ & $84(65.1)$ & \\
\hline Missing, $n(\%)$ & $4(2.0)$ & $3(2.4)$ & & $5(2.6)$ & $4(3.1)$ & \\
\hline APGAR score at 5 min, mean $\pm S D$ : & $8.41 \pm 1.39$ & $7.74 \pm 2.24$ & 0.001 & $8.37 \pm 1.43$ & $7.83 \pm 2.19$ & 0.018 \\
\hline Critically low (<3), n (\%) & $4(2.0)$ & $7(5.7)$ & & $4(2.1)$ & $7(5.4)$ & \\
\hline Fairly low (4-6), n (\%) & $10(5.1)$ & $18(14.6)$ & & $12(6.2)$ & $16(12.4)$ & \\
\hline Normal (7-10), $n(\%)$ & $171(86.8)$ & $83(67.5)$ & & $164(84.5)$ & $90(69.8)$ & \\
\hline Missing, $n(\%)$ & $12(6.1)$ & $15(12.2)$ & & $14(7.20)$ & $16(12.4)$ & \\
\hline Neonatal jaundice in 7 days of life & $178(90.40)$ & $69(56.10)$ & 0.001 & $172(88.70)$ & $76(58.9)$ & 0.001 \\
\hline Renal impairment in 7 days of life & $19(9.60)$ & $6(4.90)$ & 0.122 & $20(10.30)$ & $7(5.40)$ & 0.120 \\
\hline
\end{tabular}


Table II. Diagnosis or to treat as diagnosis

\begin{tabular}{|c|c|c|c|c|c|c|c|}
\hline \multirow{2}{*}{$\begin{array}{l}\text { ICD-10 } \\
\text { Code }\end{array}$} & \multirow{2}{*}{$\begin{array}{l}\text { Diagnosis or to treat as } \\
\text { diagnosis, } n(\%)\end{array}$} & \multicolumn{2}{|c|}{ GA } & \multirow{2}{*}{$\begin{array}{l}\text { Value } \\
\text { of } p\end{array}$} & \multicolumn{2}{|c|}{ BW } & \multirow{2}{*}{$\begin{array}{l}\text { Value } \\
\text { of } p\end{array}$} \\
\hline & & $\begin{array}{c}<37 \text { weeks } \\
(n=197)\end{array}$ & $\begin{array}{l}\geq 37 \text { weeks } \\
(n=123)\end{array}$ & & $\begin{array}{l}<2.5 \mathrm{~kg} \\
(n=194)\end{array}$ & $\begin{array}{l}\geq 2.5 \mathrm{~kg} \\
(n=129)\end{array}$ & \\
\hline P22.00 & $\begin{array}{l}\text { Respiratory distress } \\
\text { syndrome (RDS) }\end{array}$ & 68 (34.5) & $0(0.0)$ & 0.001 & 65 (33.5) & $3(2.3)$ & 0.001 \\
\hline P23.00 & Congenital pneumonia & $54(27.4)$ & $37(30.1)$ & & $52(26.8)$ & $41(31.8)$ & \\
\hline A41.90 & $\begin{array}{c}\text { Presumed sepsis (sepsis } \\
\text { unspecified organism) }\end{array}$ & $57(28.9)$ & $32(26.0)$ & & 60 (30.9) & $30(23.3)$ & \\
\hline P91.60 & $\begin{array}{l}\text { Hypoxic ischemic } \\
\text { encephalopathy (HIE) }\end{array}$ & $4(2.0)$ & $21(17.1)$ & & $4(2.1)$ & $21(16.3)$ & \\
\hline P24.01 & $\begin{array}{l}\text { Meconium aspirate } \\
\text { syndrome (MAS) }\end{array}$ & $3(1.5)$ & $25(20.3)$ & & $3(1.5)$ & $25(19.4)$ & \\
\hline A04.90 & $\begin{array}{c}\text { Bacteria intestinal infection } \\
\text { unspecified }\end{array}$ & $6(3.0)$ & $2(1.6)$ & & $4(2.1)$ & $4(3.1)$ & \\
\hline - & Others & $5(2.5)$ & $6(4.9)$ & & $6(3.1)$ & $5(3.9)$ & \\
\hline
\end{tabular}

\section{Risk factors}

Maternal risk factors such as meconium stained amniotic fluid (MSAF) showed strong and significant effects on perinatal asphyxia on both GA and BW groups. Term and NBW neonates had greater maternal risk factors, especially MSAF and perinatal asphyxia, compared to premature and LBW neonates.

Prolonged rupture of the membrane $>18 \mathrm{~h}$ had a higher incidence in premature and LBW neonates.

\section{Clinical manifestations}

The GA groups showed a significant difference in thermoregulatory symptoms, cardiac symptoms, respiratory symptoms (grunting, respiratory distress and tachypnea) and seizures, while the BW groups showed significant differences in thermoregulatory symptoms, respiratory symptoms (apnea, grunting and respiratory distress) and seizures. Premature neonates had a higher chance of presenting with respiratory symptoms such as grunting, respiratory distress and tachypnea, but had a lower incidence of seizures. Meanwhile, LBW neonates similarly had a higher probability of presenting with respiratory distress but were less likely to experience tachycardia, bradycardia and seizures (Figure 2).

\section{Empiric antibiotic treatment regimens}

The most common empiric antibiotics prescribed for both groups was the C-penicillin plus gentamicin regimen (>98.0\%). There was no significant difference in the time of initiation or treatment duration for both groups (Table III).

\section{Proven sepsis in early onset sepsis}

The number of cases of proven sepsis was equal in both groups. Premature and LBW neonates were infected with both Gram-positive and
Gram-negative microorganisms, while term and NBW were infected with Gram positive microorganisms only (Table IV).

\section{Primary treatment outcome}

A total of 178 (55.1\%) cases completed treatment without any changes to the empiric antibiotic regimen. The majority of cases in the premature and LBW groups required longer treatment duration (7 days) compared to the term and NBW groups (4-5 days). Changes in empiric antibiotic within $72 \mathrm{~h}$ occurred in $20.4 \%$ of cases while 70 $(21.7 \%)$ cases needed changes after $72 \mathrm{~h}$. The reasons for treatment failure due to changes in antibiotic within $72 \mathrm{~h}$ are shown in the highlighted box in Table V. The forest plot of treatment failure is presented in Figure 3. The overall treatment failure rate was higher in the LBW group (15.5\%). Our results showed that death due to sepsis within the first 7 days of life occurred more often in the premature and LBW groups.

\section{Secondary treatment outcome (discharge conditions)}

Discharge conditions for both groups showed significant differences (Table VI). Term and NBW neonates required less referral to other disciplines (ENT, ophthalmology, orthopedics, cardiology, etc.) during discharge $(<20.0 \%)$, and $74.0 \%$ of the cases reviewed were discharged well. More than $40.0 \%$ of premature and LBW groups needed referral to other disciplines, and around $48.0 \%$ were discharged after responding positively to antibiotic treatment.

\section{Discussion}

In the current practice, clinicians need to have a high suspicion index in order to start neonates 


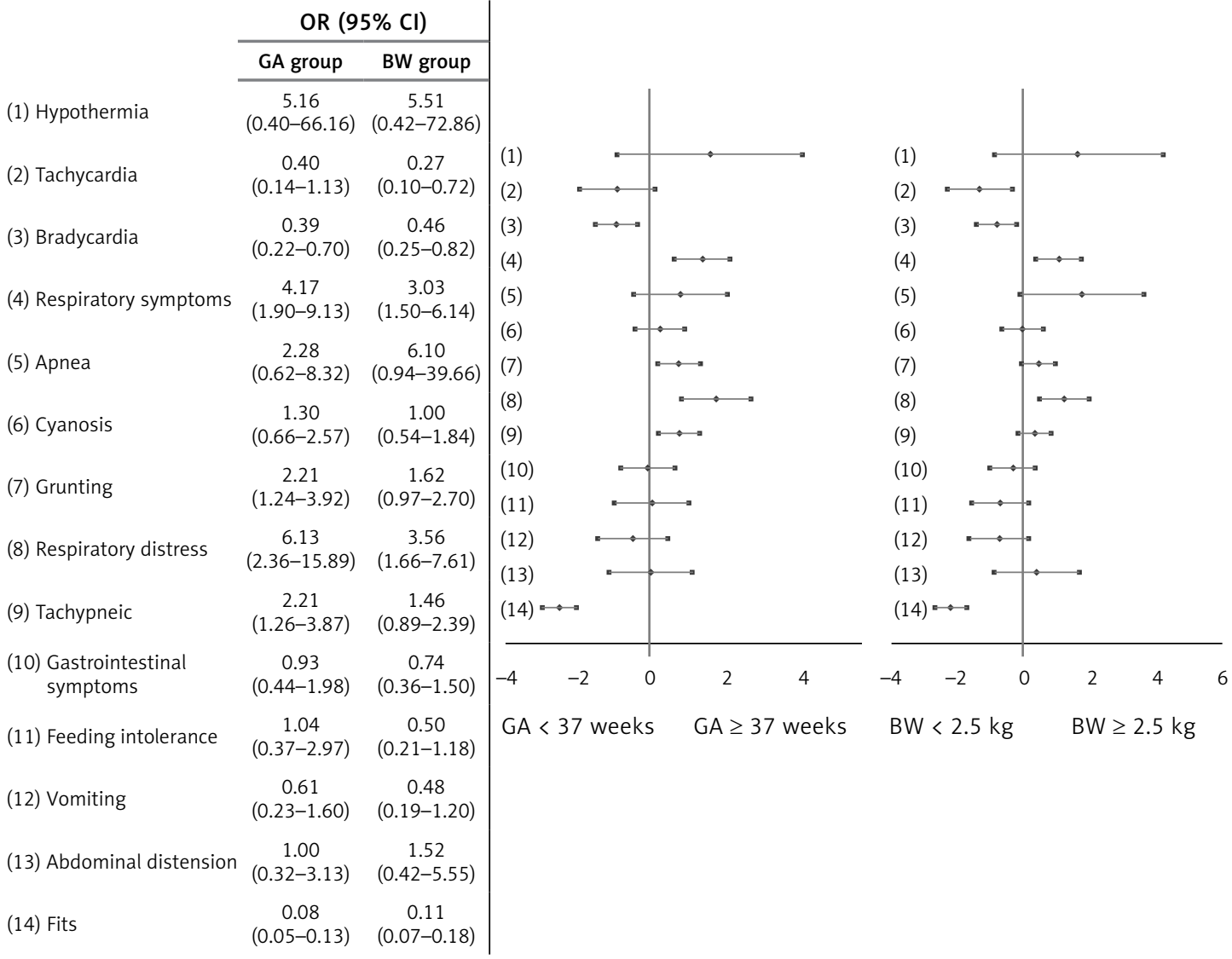

Figure 2. Forest plot of clinical manifestation

The data are presented as odds ratio (OR) (indicated by diamonds) with the $95 \% \mathrm{Cl}$ (indicated by lines). Odds ratio of the full term and normal $B W$ is 0 ; shift to the left of this line indicates lower risk in premature and low BW and vice versa.

Table III. Empiric antibiotic usage

\begin{tabular}{|c|c|c|c|c|c|c|}
\hline \multirow[t]{2}{*}{ Parameter } & \multicolumn{2}{|c|}{ GA } & \multirow{2}{*}{$\begin{array}{l}\text { Value } \\
\text { of } p\end{array}$} & \multicolumn{2}{|c|}{ BW } & \multirow{2}{*}{$\begin{array}{l}\text { Value } \\
\text { of } p\end{array}$} \\
\hline & $\begin{array}{c}<37 \text { weeks } \\
(n=197)\end{array}$ & $\begin{array}{l}\geq 37 \text { weeks } \\
(n=123)\end{array}$ & & $\begin{array}{l}<2.5 \mathrm{~kg} \\
(n=194)\end{array}$ & $\begin{array}{l}\geq 2.5 \mathrm{~kg} \\
(n=129)\end{array}$ & \\
\hline $\begin{array}{l}\text { Postnatal age (first dose antibiotic } \\
\text { given), } n(\%) \text { : }\end{array}$ & \multicolumn{5}{|c|}{0.318} & 0.349 \\
\hline $24 \mathrm{~h}$ of life & $186(94.4)$ & \multicolumn{2}{|c|}{$114(92.7)$} & $183(94.3)$ & $120(93.0)$ & \\
\hline $48 \mathrm{~h}$ of life & $9(4.6)$ & \multicolumn{2}{|c|}{$9(7.3)$} & $9(4.6)$ & $9(7.0)$ & \\
\hline $72 \mathrm{~h}$ of life & $2(1.0)$ & \multicolumn{2}{|c|}{$0(0.0)$} & $2(1.0)$ & $0(0.0)$ & \\
\hline \multicolumn{7}{|l|}{ Empiric antibiotic regimen, $n(\%)$ : } \\
\hline Ampicillin plus gentamicin & $3(1.5)$ & \multicolumn{2}{|c|}{$0(0.0)$} & $3(1.5)$ & $0(0.0)$ & \\
\hline C-penicillin plus gentamicin & $193(98.0)$ & \multicolumn{2}{|c|}{$123(100.0)$} & $191(98.5)$ & $128(99.2)$ & \\
\hline $\begin{array}{l}\text { Alternative ampicillin/penicillin } \\
\text { plus cefotaxime }\end{array}$ & $1(0.5)$ & \multicolumn{2}{|c|}{$0(0.0)$} & $0(0.0)$ & $1(0.8)$ & \\
\hline $\begin{array}{l}\text { Duration of treatment, mean } \pm \text { SD } \\
\text { [days] }\end{array}$ & $4.29 \pm 1.90$ & $4.19 \pm 1.76$ & 0.730 & $4.15 \pm 1.88$ & $4.36 \pm 1.81$ & 0.261 \\
\hline
\end{tabular}

with antibiotics as presumptive treatment [7]; nearly half $(45.9 \%)$ of neonates admitted to the NICU requiring hospitalization within the first $72 \mathrm{~h}$ of life were started with empiric antibiotics. Treating neonates for possible bacterial infection is the most common practice in NICU $[16,17]$.
The 323 cases were divided into both GA and BW groups. This is because GA is associated with changes in body composition and organ function, while BW may increase pharmacokinetic variability in neonates. For example, renal drug clearance is lower in premature neonates small for gesta- 
Table IV. Isolated microorganisms (sample taken prior to empiric antibiotic administration)

\begin{tabular}{|c|c|c|c|c|c|}
\hline \multirow[t]{2}{*}{ Variable } & \multirow{2}{*}{$\begin{array}{c}\text { Total } \\
n \text { of episodes (died) }\end{array}$} & \multicolumn{2}{|c|}{ GA } & \multicolumn{2}{|c|}{ BW } \\
\hline & & $<37$ weeks & $\geq 37$ weeks & $<2.5 \mathrm{~kg}$ & $\geq 2.5 \mathrm{~kg}$ \\
\hline \multicolumn{6}{|l|}{ Total samples tested: } \\
\hline Blood & 222 & 141 & 81 & 140 & 82 \\
\hline Placental membrane* & 2 & 1 & 1 & 1 & 1 \\
\hline \multicolumn{6}{|l|}{ Gram-positive: } \\
\hline Bacillus sp. (Gram positive bacilli) & $5(0)$ & 2 & 3 & 1 & 4 \\
\hline Group B streptococci & $1^{\wedge}(0)$ & - & $1^{\wedge}$ & & $1^{\wedge}$ \\
\hline Streptococcus pneumonia & $1(1)$ & - & 1 & 1 & - \\
\hline \multicolumn{6}{|l|}{ Gram-negative: } \\
\hline Stenotrophomonas (xantho) maltophi & $1(0)$ & 1 & - & 1 & - \\
\hline Haemophilus influenza & $1(0)$ & 1 & - & 1 & - \\
\hline Sphingomonas paucimobilis & $1(0)$ & 1 & - & 1 & - \\
\hline Total episodes & $10(1)$ & 5 & 5 & 5 & 5 \\
\hline
\end{tabular}

${ }^{\wedge}$ Eye swab. *Amniotic fluid and amniotic/placental membrane cultures.

tional age than those of appropriate size for gestational age [18]. Earlier evidence has shown that both GA and BW are important factors in determining drug dose and frequency in neonates [19]. This classification is suitable for comparing treatment outcomes, especially in neonates.

In this study, nearly $50.0 \%$ of the mothers received antibiotics, and their babies were treated as suspected EOS. This is expected since maternal risk factors and intrapartum complications were the main contributing factors for suspected EOS in neonates. According to the Morbidity and Mortality Weekly Report (MMWR) in 2010 [20], pregnant women with a risk of infection, including positive recto-vaginal culture, chorioamnionitis, prolonged rupture of membranes or premature delivery, should be covered with antibiotic prophylaxis during pregnancy or in the intrapartum period for prevention of perinatal group B streptococcal infection $[20,21]$. The results also demonstrate that neonates of mothers who received intrapartum antibiotic prophylaxis (IAP) were more likely to be treated for suspected EOS with a prolonged hospital stay [22].

Almost $50.0 \%$ of the neonates in GA and BW groups were delivered through LSCS. This is because LSCS is classified as a clean-contaminated operation and IAP was given peri-operatively to reduce the risk of infection and endometritis [23].

In our study, respiratory symptoms were significantly associated with prematurity. Prematurity is associated with many complications in neonates such as increased risk of infection [20] and risk of respiratory distress syndrome (RDS) [24]. The majority of the premature group in our study was diagnosed with RDS, followed by suspected sepsis and congenital pneumonia. Respiratory distress occurs in premature infants as a result of non-fully-developed lung anatomy and surfactant deficiency [25]. Another study showed that neonates with respiratory distress need to be treated with oxygenation, ventilation and surfactant replacement [24]. This is in agreement with our findings, where there was significant ventilator and surfactant use in premature neonates.

Meconium stained amniotic fluid occurs in $13.0 \%$ of deliveries, and at least $5.0 \%$ of those cases presented with MAS, typically in term and postterm neonates $[26,27]$. The MAS may cause hypoxia and significant respiratory distress after delivery [24]. Our study found that the risk of MSAF and perinatal asphyxia was significantly associated with term neonates. The majority of term neonates were diagnosed with congenital pneumonia and presented with respiratory symptoms followed by suspected sepsis, MAS and HIE. Seizures are clinical manifestations that are significantly associated with term neonates; this was consistent with the effect of MAS and HIE in neonates.

Furthermore, EOS normally manifests as pneumonia and less commonly as meningitis and sepsis [7]. Our study shows that respiratory symptoms were common in both term and premature neonates, which is in agreement with a study conducted in the University of Michigan Health System [28]. The choice of empiric antibiotic is dependent on the probable pathogens and strong perinatal history, including maternal symptoms and culture. The current study findings show that more than $92.0 \%$ of the total 
Table V. Primary treatment outcome

\begin{tabular}{|c|c|c|c|c|c|}
\hline \multirow[t]{2}{*}{ Parameter } & \multicolumn{2}{|c|}{ GA } & \multicolumn{2}{|c|}{ BW } & \multirow{2}{*}{$\begin{array}{c}\text { Total } \\
\text { cases } \\
(n=323)\end{array}$} \\
\hline & $\begin{array}{l}<37 \text { weeks } \\
(n=197)\end{array}$ & $\begin{array}{l}\geq 37 \text { weeks } \\
(n=123)\end{array}$ & $\begin{array}{l}<2.5 \mathrm{~kg} \\
(n=194)\end{array}$ & $\begin{array}{l}\geq 2.5 \mathrm{~kg} \\
(n=129)\end{array}$ & \\
\hline $\begin{array}{l}\text { Completed empiric antibiotic treatment } \\
\text { without changes: }\end{array}$ & & & & & $178(55.1)$ \\
\hline 3 days & $18(9.1)$ & $16(13.0)$ & $20(10.3)$ & $14(10.9)$ & \\
\hline $3.5-4$ days & $8(4.1)$ & $13(10.6)$ & $9(4.6)$ & $12(9.3)$ & \\
\hline $4.5-5$ days & $21(10.7)$ & $27(21.9)$ & $20(10.3)$ & $28(21.7)$ & \\
\hline 6 days & $13(6.6)$ & $6(4.9)$ & $11(5.7)$ & $8(6.2)$ & \\
\hline 7 days & $39(19.8)$ & $17(13.8)$ & $34(17.5)$ & $22(17.1)$ & \\
\hline Total cases & $99(50.3)$ & $79(64.2)$ & $94(48.5)$ & $84(65.1)$ & \\
\hline Changes of antibiotic within $72 \mathrm{~h}$ : & & & & & $66(20.4)$ \\
\hline No improvement & $14(7.1)$ & $6(4.9)$ & $16(8.3)$ & $4(3.1)$ & Treatment \\
\hline Meningitis or suspicion of meningitis & $4(2.0)$ & $1(0.8)$ & $5(2.6)$ & $0(0.0)$ & failure \\
\hline $\begin{array}{l}\text { NEC or suspicion of other abdominal } \\
\text { infection }\end{array}$ & $5(2.5)$ & $2(1.6)$ & $5(2.6)$ & $2(1.6)$ & \\
\hline Microorganism resistant to antibiotic & $2(1.0)$ & $0(0.0)$ & $2(1.0)$ & $0(0.0)$ & \\
\hline Dosing adjustment (optimize/reduce) & $2(1.0)$ & $2(1.6)$ & $1(0.5)$ & $4(3.1)$ & \\
\hline Renal impairment/gentamicin toxicity & $7(3.6)$ & $4(3.3)$ & $7(3.6)$ & $5(3.9)$ & \\
\hline Others & $8(4.1)$ & $7(5.7)$ & $9(4.6)$ & $6(4.7)$ & \\
\hline Total cases & $42(21.3)$ & $22(17.9)$ & $45(23.2)$ & $21(16.3)$ & \\
\hline Changes of antibiotic after $72 \mathrm{~h}$ : & & & & & $70(21.7)$ \\
\hline No improvement & $30(15.2)$ & $11(8.9)$ & $31(15.9)$ & $10(7.7)$ & \\
\hline Meningitis or suspicion of meningitis & $1(0.5)$ & $1(0.8)$ & $1(0.5)$ & $1(0.8)$ & \\
\hline $\begin{array}{l}\text { NEC or suspicion of other abdominal } \\
\text { infection }\end{array}$ & $14(7.1)$ & $1(0.8)$ & $11(5.7)$ & $4(3.1)$ & \\
\hline Microorganism resistant to antibiotic & $1(0.5)$ & $0(0.0)$ & $1(0.5)$ & $0(0.0)$ & \\
\hline Dosing adjustment (optimize/reduce) & $2(1.0)$ & $2(1.6)$ & $2(1.0)$ & $2(1.6)$ & \\
\hline Renal impairment/gentamicin toxicity & $4(2.0)$ & $2(1.6)$ & $5(2.6)$ & $2(1.6)$ & \\
\hline Total case & $52(26.4)$ & $17(13.8)$ & $51(26.3)$ & $19(14.7)$ & \\
\hline Overall treatment failure: & & & & & $36(11.15)$ \\
\hline Changes of antibiotic within $72 \mathrm{~h}$ & 25 & 9 & 28 & 6 & \\
\hline $\begin{array}{l}\text { Death within seven days (death/death }+ \\
A B \text { changes) }\end{array}$ & $1 / 3$ & $0 / 1$ & $2 / 3$ & $0 / 1$ & \\
\hline Total cases & $26(13.2)$ & $9(7.3)$ & $30(15.5)$ & $6(4.7)$ & \\
\hline
\end{tabular}

cases started empiric antibiotics within $24 \mathrm{~h}$ and more than $98.0 \%$ started with the combination of intravenous penicillin plus gentamicin, which follows the recommendations in the National Antibiotics Guidelines set out by the Malaysian Ministry of Health for the empiric treatment of suspected EOS [9].

Blood culture was the most common investigation performed prior to empiric antibiotic admin- istration with a diagnosis of a serious infection [29]. However, cultures with proven EOS remained scarce among the studied neonates, which was further reflected by the low number of positive cultures observed in the present study (3.1\%), similar to what has been reported in the literature $[6,30]$. These findings show that the choice of antibiotics used for EOS in the present study on neonates was effective. 


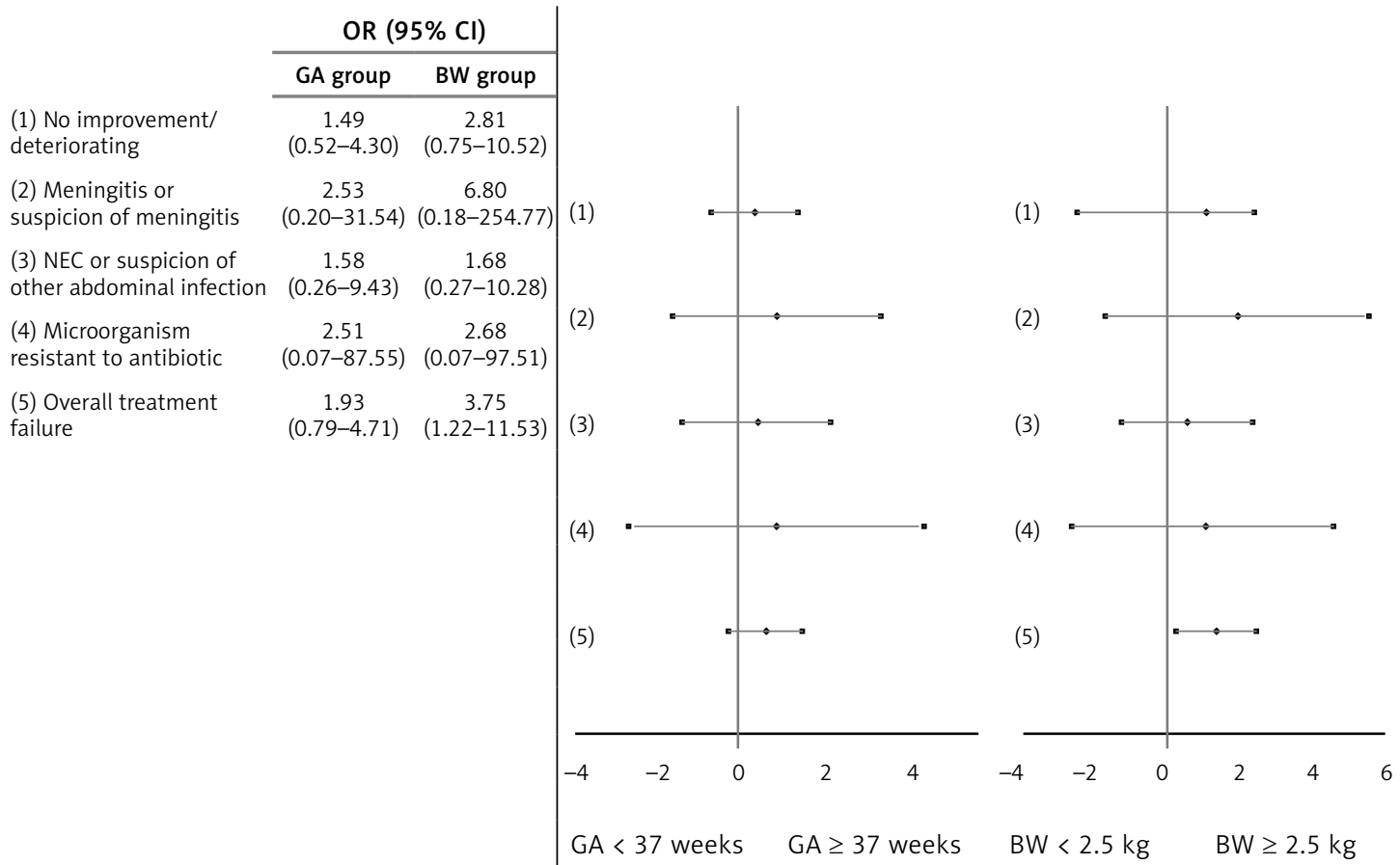

Figure 3. Forest plot of treatment failure (changes of antibiotic within $72 \mathrm{~h}$ )

The data are presented as odds ratio (OR) (indicated by diamonds) with the $95 \% \mathrm{Cl}$ (indicated by lines). Odds ratio of the full term and normal BW is 0 ; shift to the left of this line indicates lower risk in premature and low BW and vice versa.

Table VI. Discharge condition

\begin{tabular}{|c|c|c|c|c|c|c|}
\hline \multirow[t]{2}{*}{ Discharge condition } & \multicolumn{2}{|c|}{$\mathrm{GA}$} & \multirow{2}{*}{$\begin{array}{l}\text { Value } \\
\text { of } p\end{array}$} & \multicolumn{2}{|c|}{ BW } & \multirow{2}{*}{$\begin{array}{l}\text { Value } \\
\text { of } p\end{array}$} \\
\hline & $\begin{array}{c}<37 \text { weeks } \\
(n=197)\end{array}$ & $\begin{array}{c}\geq 37 \text { weeks } \\
(n=123)\end{array}$ & & $\begin{array}{l}<2.5 \mathrm{~kg} \\
(n=194)\end{array}$ & $\begin{array}{l}\geq 2.5 \mathrm{~kg} \\
(n=129)\end{array}$ & \\
\hline $\begin{array}{l}\text { Well or with follow-up (G\&D or TSB } \\
\text { monitoring) }\end{array}$ & $95(48.2)$ & $92(74.8)$ & 0.001 & $93(47.9)$ & $96(74.4)$ & 0.001 \\
\hline With referral to other clinic & $85(43.1)$ & $22(17.9)$ & & $82(42.3)$ & $25(19.4)$ & \\
\hline Transfer well to other hospital & $4(2.0)$ & $2(1.6)$ & & $4(2.1)$ & $2(1.6)$ & \\
\hline AOR & $0(0.0)$ & $3(2.4)$ & & $0(0.0)$ & $3(2.3)$ & \\
\hline Death & $13(6.6)$ & $4(3.3)$ & & $15(7.7)$ & $3(2.3)$ & \\
\hline
\end{tabular}

The majority of premature and LBW neonates required a longer duration of treatment (7 days) compared to term and NBW neonates (4.55 days) to complete the empiric treatment. The reasons for these observations are risk factors such as prematurity, LBW, low APGAR score, prolonged rupture of the membrane and mothers who received intrapartum antibiotics [31].

In this study, the treatment success rate was 89.0\% for all neonates; LBW neonates had a higher risk of treatment failure. A previous study reported 10.0-20.0\% treatment failure in suspected or proven EOS administered with penicillin or ampicillin plus gentamicin antibiotic therapy. These authors also reported that premature and LBW neonates may have an increased risk of treatment failure [6].
By definition, discharge is the event where warded neonates are allowed to go home with or without a medical appointment and follow-up. In practice, the discharge decision will be based on the neonate's medical condition and the parents' readiness to take care of their babies at home [32]. Discharge conditions are important to ensure that the neonates are medically stable prior to discharge. In this study, the neonate discharge conditions were significantly different between the GA and BW groups $(p<0.5)$. Most of the term and NBW neonates were discharged well, while almost half of premature and LBW neonates required referral to other disciplines due to prematurity complications such as chronic lung disease, retinopathy of prematurity, intraventricular hemorrhage, 
cardiovascular disorders, hearing disorders and necrotizing enterocolitis.

In conclusion, most of the admitted neonates with suspected EOS in the studied facility presented with respiratory symptoms. The PROM less than $18 \mathrm{~h}$ may increase the risk of EOS in premature and LBW neonates, and MSAF was the main factor that contributed to EOS in term and NBW neonates. Intravenous penicillin plus gentamicin prescribed within the first $24 \mathrm{~h}$ of life was effective in EOS prevention, with a treatment success rate of $89.0 \%$. However, LBW neonates may have a greater risk of treatment failure.

\section{Acknowledgments}

This work was partially supported by the Research Acculturation Grant Scheme (RAGS), Malaysia (RAGS/2013/UITM/SKK02/3). The authors would like to express their gratitude to the Ministry of Education, Malaysia and Universiti Teknologi MARA, Malaysia for partial financial support for this research.

\section{Conflict of interest}

The authors declare no conflict of interest.

\section{References}

1. World Health Organization. Neonatal and Perinatal Mortality: Country, regional and global estimates, Available at: http://whqlibdoc.who.int/publications/2006/ 9241563206_eng.pdf.

2. Ganatra HA, Stoll BJ, Zaidi AK. International perspective on early-onset neonatal sepsis. Clin Perinatol 2010; 37: 501-23.

3. Vergnano S, Sharland M, Kazembe P, Mwansambo C, Heath PT. Neonatal sepsis: an international perspective. Arch Dis Child Fetal Neonatal Ed 2005; 90: F220-4.

4. Cordero L, Ayers LW. Duration of empiric antibiotics for suspected early-onset sepsis in extremely low birth weight infants. Infect Control Hosp Epidemiol 2003; 24: 662-6.

5. Stoll BJ, Hansen NI, Higgins RD, et al. Very low birth weight preterm infants with early onset neonatal sepsis: the predominance of Gram-negative infections continues in the National Institute of Child Health and Human Development Neonatal Research Network, 2002-2003. Pediatr Infect Dis J 2005; 24: 635-9.

6. Metsvaht T, Pisarev H, IImoja ML, et al. Clinical parameters predicting failure of empirical antibacterial therapy in early onset neonatal sepsis, identified by classification and regression tree analysis. BMC Pediatr 2009; 9: 72.

7. WHO Collaborating Centre for Training and Research in New-born Care. Teaching Aids on New-born care. Available at: http://www.newbornwhocc.org/nnf.htm.

8. Naher BS, Mannan MA, Noor K, Shahidullah M. Role of pro-calcitonin and $\mathrm{C}$-reactive protein in the diagnosis of neonatal sepsis. Bangladesh Med Res Counc Bull 2011 37: 40-6.

9. Ministry of Health-Malaysia. National Antibiotic Guideline 2008, pg 181, Available at; http://apps.who.int/ medicinedocs/documents/s17800en/s17800en.pdf.
10. Cohen-Wolkowiez M, Moran C, Benjamin DK, et al. Early and late onset sepsis in late preterm infants. Pediatr Infect Dis J 2009; 28: 1052-6.

11. Bhat R, Kumar N. Outcome of sepsis evaluations in very low birth weight premature neonates. J Clin Diagn Res 2009; 3: 1847-52.

12. Varga M, Sixta B, Bem R, Matia I, Jirkovska A, Adamec M. Application of gentamicin-collagen sponge shortened wound healing time after minor amputations in diabetic patients - a prospective, randomised trial. Arch Med Sci 2014; 10: 283-7.

13. Hassan Y, Aziz NA, Kassab Y, et al. How to help patients to control their BP? Blood pressure control and its predictor Arch Pharm Pract 2014; 5: 153-61.

14. Hadi MA, Helwani R, Long CM. Facilitators and barriers towards adverse drug reaction reporting: perspective of Malaysian hospital pharmacists. J Pharm Health Serv Res 2013; 4: 155-8.

15. Manan MM, Rusli RA, Ang WC, Al-Worafi YMA, Ming LC. Assessing the pharmaceutical care issues of antiepileptic drug therapy in hospitalised epileptic patients. J Pharm Pract Res 2014; 44: 83-8.

16. Gerdes JS. Diagnosis and management of bacterial infections in the neonate. Pediatr Clin North Am 2004; 51 : 939-59.

17. Sadowska-Krawczenko I, Jankowska A, Kurylak A. Healthcare-associated infections in a neonatal intensive care unit. Arch Med Sci 2012; 8: 854-8.

18. Allegaert K, Anderson BJ, van den Anker JN, Vanhaesebrouck S, de Zegher F. Renal drug clearance in preterm neonates: relation to prenatal growth. Ther Drug Monit 2007; 29: 284-91.

19. Kearns GL, Abdel-Rahman SM, Alander SW, Blowey DL, Leeder JS, Kauffman RE. Developmental pharmacology-drug disposition, action, and therapy in infants and children. N Engl J Med 2003; 349: 1157-67.

20. Verani JR, McGee L, Schrag SJ. Prevention of perinatal group B streptococcal disease-revised guidelines from CDC. MMWR Recomm Rep 2010; 59: 1-36.

21. Kornacki J, Goździewicz T, Łabędzka I, et al. The influence of preterm premature rupture of membranes on maternal and neonatal outcome. Arch Med Sci 2009; 5: 222-8.

22. Glasgow TS, Speakman M, Firth S, James B, Byington CL, Young PC. Clinical and economic outcomes for term infants associated with increasing administration of antibiotics to their mothers. Paediatr Perinat Epidemiol 2007; 21: 338-46.

23. Gunn B, Ali S, Abdo-Rabbo A, Suleiman B. An investigation into perioperative antibiotic use during lower segment caesarean sections (LSCS) in four hospitals in Oman. Oman Med J 2009; 24: 179-83.

24. Hermansen $\mathrm{CL}$, Lorah $\mathrm{KN}$. Respiratory distress in the newborn. Am Fam Physician 2007; 76: 987-94.

25. Nkadi PO, Merritt TA, Pillers DA. An overview of pulmonary surfactant in the neonate: genetics, metabolism, and the role of surfactant in health and disease. Mol Genet Metab 2009; 97: 95-101.

26. Gelfand SL, Fanaroff JM, Walsh MC. Meconium stained fluid: approach to the mother and the baby. Pediatr Clin North Am 2004; 51: 655-67.

27. Yurdakok M. Meconium aspiration syndrome: do we know? Turk J Pediatr 2011; 53: 121-9.

28. Attar M, Becker MA, Dechert RE, Donn SM. Variability in the response to dexamethasone treatment in term neonates with respiratory failure. Arch Med Sci 2009; 5: 427-33. 
29. Weinstein MP. Blood culture contamination: persisting problems and partial progress. J Clin Microbiol 2003; 41: 2275-8.

30. Clark RH, Bloom BT, Spitzer AR, Gerstmann DR. Empiric use of ampicillin and cefotaxime, compared with ampicillin and gentamicin, for neonates at risk for sepsis is associated with an increased risk of neonatal death. J Am Acad Pediatr 2006; 117: 67-74.

31. Cotten CM, Taylor S, Stoll B, et al. Prolonged duration of initial empirical antibiotic treatment is associated with increased rates of necrotizing enterocolitis and death for extremely low birth weight infants. Pediatrics 2009; 123: 58-66.

32. Profit J, McCormick MC, Escobar GJ, et al. Neonatal intensive care unit census influences discharge of moderately preterm infants. Pediatrics 2007; 119: 314-9. 